\title{
Global climate patterns explain range-wide synchronicity in survival of a migratory seabird
}

Stephanie Jenouvrier, Jean-Claude Thibault, Anne Viallefont, Patrick Vidal, Dietrich Ristow, Jean-Louis Mougin, Pierandrea Brichetti, John J. Borg, Vincent Bretagnolle.

S. Jenouvrier and V. Bretagnolle, Centre d'Etudes Biologiques de Chizé, Centre National de la Recherche Scientifique, F-79360 Villiers en Bois, France - A.Viallefont, Laboratoire de Biométrie et Biologie Évolutive. Université Lyon 1, 69622 Villeurbanne - P. Vidal, Parc Maritime des Iles du Frioul, CEEP, Sémaphore de Pomègues, Le Frioul, 13001 Marseille J.-C Thibault Muséum National d'Histoire Naturelle, Département Systématique et Evolution, 57 Rue Cuvier, F-75231 Paris - D. Ristow, Pappelstrasse, 35, D-8579 Neubiberg, Germany - J.-L. Mougin, Laboratoire de Zoologie (Mammifères et oiseaux), 55 rue Buffon, F-75005 Paris, France - P. Brichetti, Centro Italiano Studi Ornitologici, Via V. Veneto 30, 25029 Verolavecchia, Italy - J.J. Borg, National Museum of Natural History, Vilhena Palace, Medina, Malta.

Corresponding author: Stéphanie Jenouvrier, present address: Woods Hole Oceanographic Institution, Woods Hole, Massachusetts 02543. Phone: (508) 289-3245; Fax: (508) 4572134 ; E-mail: sjenouvrier@whoi.edu.

Key-words: adult survival, capture-recapture models, synchrony, climate, Southern Oscillation, Cory's shearwater.

Running title: Global climate and synchronicity in survival 


\section{Abstract}

To predict the impact of climate change over the whole species distribution range, comparison of adult survival variations over large spatial scale is of primary concern for long-lived species populations that are particularly susceptible to decline if adult survival is reduced. In this study, we estimated and compared adult survival rates between 1989 and 1997 of six populations of Cory's shearwater (Calonectris diomedea) spread across $4600 \mathrm{~km}$ using capture-recapture models.

We showed that mean annual adult survival rates are different among populations along a longitudinal gradient and between sexes. Variation in adult survival is synchronized among populations, with three distinct groups: (1) both females and males of Corsica, Tremiti and Selvagem (annual survival range 0.88-0.96); (2) both females and males of Frioul and females from Crete (0.82-0.92); and (3) both females and males of Malta and males from Crete $(0.74-0.88)$. The total variation accounted for by the common pattern of variation is on average $71 \%$, suggesting strong environmental forcing. At least $61 \%$ of the variation in survival is explained by the Southern Oscillation Index fluctuations. We suggested that Atlantic hurricanes and storms during La Niña years may increase adult mortality for Cory’s shearwater during winter months. For long-lived seabird species, variation in adult survival is buffered against environmental variability, although extreme climate conditions such as storms significantly affect adult survival. The effect of climate at large spatial scales on adult survival during the non-breeding period may lead to synchronization of variation in adult survival over the species' range and have large effects on the meta-population trends. One can thus worry about the future of such long-lived seabirds species under the predictions of higher frequency of extreme large scale climatic events. 


\section{Introduction}

The global climate is warming, with important consequences for animals and plant populations (Walther et al. 2002). Population changes are caused by variation in vital rates (demographic parameters), and many long-lived species have low population growth rates resulting from their life histories (small litter size, late recruitment and high adult survival, Stearns 1992). Population growth rates for long-lived species are strongly influenced by adult survival (Lebreton and Clobert 1990). Adult survival may vary little, because variability is selectively disadvantageous for long-lived iteroparous species, and the variability of vital rates that has greatest impact on the population growth rate should be low (i.e environmental canalization process; Saether and Bakke 2000, Gaillard and Yoccoz 2003).

Adult survival of long-lived species is affected by climate variation (e.g. Jenouvrier et al. 2003). The effect of climate may vary within a year according to the life history of the species (e.g. breeding and wintering seasons, see Jenouvrier et al. 2005), and may depend on the severity of environmental change at these different times of the year. Extreme climate events may particularly reduce adult survival, ultimately causing the population to crash (e,g. emperor penguin Aptenodytes forsteri, Jenouvrier et al. 2005; barn owl Tyto alba, Altwegg et al. 2006).

Climate effects could be critical during the non-breeding season for long-lived migratory species when individuals from a wide range of breeding populations migrate to a same area, because any reduction in adult survival will cause a decrease of the whole metapopulation. Moreover, climatic influence during the non-breeding season may cause synchrony in adult survival variability between breeding populations over a large spatial range (Schaub et al. 2005, Harris et al. 2005), and potentially increase the risk of species extinction (Royama 1992). Therefore, comparison of adult survival variations over a wide 
spatial range is of primary concern to study the influence of climate on populations, and hence predict the impact of climate changes over the whole species distribution range.

Comparative studies focusing on variation in the vital rates within a species and covering a substantial part of the species' range are very rare (Frederiksen et al. 2005). Most of the comparative studies to date compare previously published data (e.g. Frederiksen et al. 2005). Few species are studied at the individual level with capture-recapture in population across their geographical range, to provide a rigorous joint analysis of original data from all sites (but see Harris et al. 2005). Here, we compared the variation of adult survival of a procellariiformes seabird (i.e. petrel), the Cory's Shearwater (Calonectris diomedea), over a substantial range of its distribution. We estimated adult survival with a joint analysis from the original capture-recapture data for 6 breeding populations over $4600 \mathrm{~km}$ apart during 9 years.

Adult survival of several petrel species is affected by climate variability (e.g. Jenouvrier et al. 2003), and also other factors that may interact with the effect of climate variability, such as sex (e.g. Jenouvrier et al. 2005), density-dependence (Barbraud and Weimerskirch 2003), and fisheries (Rolland et al. 2007),. For Cory's Shearwater, several potential non-exclusive factors may affect adult survival, including physical factors (e.g large climatic oscillation; Brichetti et al. 2000), biological factors related to the environment (e.g. oceanographic productivity), factors specific to the species (e.g. sex, body size and migration pattern), and finally human factors (harvesting and fisheries bycatch). Because seabird activity varies with season, these different factors may act at different spatial scales and time periods within a year. We first compared the average Cory's Shearwater annual adult survival between the 6 populations and between sexes. The Cory's Shearwater is sexually dimorphic (Ristow and Wink 1980) and differences between sexes are thus expected. Moreover, we expected a longitudinal gradient in adult survival due to geographical variation in ocean 
productivity (Margalef 1985, Caddy et al. 1995, Freudenthal et al. 2002), body size (Rabouam et al. 1998) and migration patterns (Ristow et al. 2000). Human impacts on adult survival also differed between the breeding sites; Cory's shearwater is harvested in the Sicily channel and is commonly fisheries bycatch in the Mediterranean (Belda and Sanchez 2001).

Secondly, we studied temporal variability in adult survival. During the breeding season, the potential factors affecting survival involve specific local processes. Since the 6 breeding populations studied here were spread over $4600 \mathrm{~km}$, we expected differences in temporal variation among populations if environmental conditions affect survival mainly during the breeding season. During the non-breeding season, seabirds have a widespread distribution across vast oceanic ranges and can simply select a different area with better climate or trophic conditions (Harris et al. 2005). Therefore, during the non-breeding season, factors affecting adult survival variations are likely extreme events occurring at large spatial scales. Such events have the potential to result in synchrony in time series of adult survival (Schaub et al. 2005). Moreover, we expect little variability in adult survival under the environmental canalization hypothesis (Saether and Bakke 2000, Gaillard and Yoccoz 2003), although it would be surprising if adverse climate and trophic conditions did not affect survival at all. For instance, many seabird wrecks, (i.e. large numbers of seabirds washing ashore), appear to be related to periods of stormy weather (Hudson 1985).

Finally, we studied the potential influence of large scale climate oscillations on temporal adult survival variations. Causal relationships between adult survival and large scale climatic phenomena are not easily identified (Sandvik et al. 2005), although large-scale climatic oscillations are remarkably good predictors of ecological responses to climate (Hallett et al. 2004). Large-scale climatic oscillations are defined as temporal fluctuations of pressure anomalies, and are treated as a 'proxy' for different climatic processes (Stenseth et al. 2003). Large scale climatic oscillations affect the local climate and oceanographic 
constraints (Ottersen et al. 2001) and thus may affect adult survival of long-lived species directly by increasing mortality during extreme environmental events (e.g Brichetti et al. 2000), or indirectly through its effect on the abundance and distribution of prey (e.g. Sandvik et al. 2005). We tested whether variability in adult survival is driven by large scale climatic processes through direct or indirect effects. Atlantic hurricanes and storms during La Niña years of the Southern Oscillation (SO), may have directly affected adult survivorship by increasing mortality of migrating birds (Brichetti et al. 2000). The North Atlantic Oscillation (NAO) may be indirectly affecting adult survivorship by affecting the food web (Stenseth et al. 2004). 


\section{Material and methods}

\section{Study species and sites}

Cory's Shearwaters are typical long-lived seabirds, with low fecundity (a single egg is laid per year), low first-year survival (Jenouvrier et al. 2008), and delayed sexual maturity (see review in Thibault et al. 1997, Mougin et al. 2000, Jenouvrier et al. 2008). The Cory's Shearwater is sexually dimorphic (Ristow and Wink 1980) and there are sex differences in vocalizations (Bretagnolle and Lequette 1990). They forage at sea and feed on fish, molluscs and offal (Sarà 1993). They breed on islands and cliffs from the end of February to midOctober. Data on their wintering range are scarce, but observations suggest that the wintering area is very large and encompasses the entire Atlantic, potentially reaching the Indian Ocean (Thibault et al. 1997). Birds from Atlantic populations seem to winter more westward in the Atlantic than those from the Mediterranean (Ristow et al. 2000), although they are both observed in similar areas in different abundances (Camphuysen and Van Der Meer 2001).

Studies were carried out on six breeding population of Cory's shearwater on six islands from the eastern Atlantic to the eastern Mediterranean (Fig. 1). At the western and eastern edges of the Cory's shearwater breeding distribution range, the population number at Selvagem Island is the highest (30,000 birds) and at Crete the lowest (500-700 birds).

\section{Data collection}

At each population, birds were caught in their burrows or at the burrow's entrance and ringed. In subsequent years, they were recaptured intensively in annually visited plots. The period of capture-recapture differed among population because the present comparison was not intended when the authors independently started their field work.

Birds were sexed on the basis of voice, bill measurements (length and height), or the sex of their breeding partner. Cory's shearwater body size decreases gradually eastward from the Atlantic to the Mediterranean (Thibault et al. 1997, Rabouam et al. 1998). Weight is used as a 
proxy of body size, although weight variations are influenced by stomach contents and fat stores, and thus showed important variations within a population.

\section{Environmental variables}

We tested the effect of Southern Oscillation Index (SOI available at: http: //www.cru.uea.ac.uk/cru/data/soi.htm) and the North Atlantic Oscillation index, (NAO, http: //www.cgd.ucar.edu/cas/jhurrell/indices.html) on adult survival of Cory's shearwater. The SO is a large scale oscillation in atmospheric mass between the southeastern (Darwin) and southwestern (Tahiti) Pacific waters, and the NAO between the subtropical high (Azores) and the polar low (Iceland). We used the annual indices averaged over the entire year for SOI because previous time series analysis detected strong annual variation and no significant seasonal variability in the SOI fluctuations (unpublished results), and over winter for the NAO (Steenseth et al. 2004) .

The effect of the Southern Oscillation is most pronounced in the south-eastern Pacific Ocean, although other marine ecosystems are also affected, such as in the Southern Atlantic (e.g Duffy 1990) where Cory's Shearwaters spend the winter. Sustained negative values of the SOI indicate El Niño episodes, while positive values indicate La Niña episodes. La Niña episodes favor tropical storms and hurricanes in the Atlantic that likely influence the survivorship of Cory's Shearwaters by causing increased heat loss, displacing birds to areas with less food, or making foraging more difficult because common fish prey species move deeper into the water column (Brichetti et al. 2000).

The NAO may affect seabird mortality directly (wind) and/or indirectly (prey availability), although several studies suggest that these effects are indirect rather than direct (Harris et al. 2005, Sandvik et al. 2005). In our case, because birds wintered in the Southern Atlantic and the equatorial zone, a direct effect of the NAO on mortality is not expected 
because the storms occur in the North Atlantic Ocean. NAO may affect seabird mortality during the breeding season through its lagged effects on the abundance of lower trophic level species (e.g. phytoplankton, zooplankton and fish, Stenseth et al. 2004). Because Cory's shearwaters forage on lower trophic species with short life cycle, lags are expected to be seasonal rather than yearly. Therefore, we assumed a lag of one season because we used the NAO during winter to test its effect on adult survival during the following breeding season.

\section{Data analysis and modelling}

The analysis is based on capture-recapture histories of birds of unknown age when ringed, and recaptured in the subsequent years as breeders from populations where the same burrows have been checked each year. Data sets differed in length, and the analysis was restricted to the common period from 1989 to 1997.

We used capture-mark-recapture (CMR; Lebreton et al. 1992) models to estimate adult annual survival rates. CMR models distinguish survival (noted $\Phi$ ), defined as the probability that a Shearwater alive at year $t$ survives at year $t+1$, and recapture probabilities (noted $\mathrm{P}$ ), defined as the probability that a Shearwater alive at year $t$ is caught during the breeding season of year $t$. The Cormack-Jolly-Seber model (CJS) is noted $\Phi_{t}, \mathrm{P}_{t}$, where both survival and capture probabilities varied freely over time, denoted $t$.

Two classical sources of lack of fit in capture-recapture studies arise from transient and trap dependence effects. The transient effect arises with birds that disperse from the study population in spite of breeding, or birds that breed in an inaccessible crevice nearby in future years (Tavechia et al. 2001). Trap dependence and especially trap happiness (a bird seen in year $t$ is much more likely to be seen in year $t+1$ than a bird not seen in year $t$ ) is common in seabird capture-recapture data because most of seabirds were extremely faithful to their breeding colony (Jenouvrier et al. 2005). To detect transient and trap dependent effects, goodness of fit (GOF) tests for the CJS model were computed for each location and sex (see 
Table 1 in Appendix) using the program U-Care (Choquet et al. 2005). Overall, there were large discrepancies between study sites and sex. Trap happiness (denoted by $m$ ) is detected for males in Corsica and females in Crete, and the trap dependence models $\left(\Phi_{t}, \mathrm{P}_{t^{*} m}\right)$ fits the data ( $\mathrm{p}=0.13$ and $\mathrm{p}=0.85$ respectively). A transient effect is detected only for Selvagem birds for both sexes and is denoted by $a 2$ for two classes of apparent "age" (i.e. time elapsed since marking). The transient model $\left(\Phi_{t^{*} a 2}, \mathrm{P}_{t}\right)$ fits the data $(\mathrm{p}=0.84$ and $\mathrm{p}=0.23$ for females and males respectively).

The umbrella (i.e most general) model is thus $\left(\Phi_{t^{*} s}\right.$ Corsica, Crete, Frioul, Malta, Tremiti $\Phi_{t^{*} *^{*} a 2 \text { Selvagem }}, \mathrm{P}_{t}$

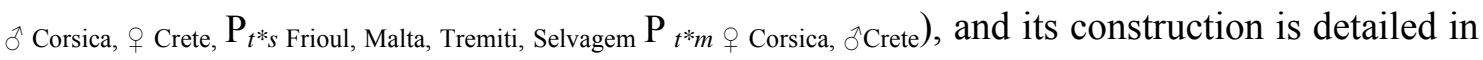
the Appendix (see also Gimenez et al. 2003 for model development, and Frederiksen et al. 2004 and Crespin et al. 2006 for applications to other species). From the umbrella model, simpler models are fitted successively and Akaike's information criterion corrected for small sample size $\left(\mathrm{AIC}_{\mathrm{c}}\right.$ see Anderson and Burnham 1999) is used for model comparison. The best model is the one with the lowest AICc, i.e the most parsimonious model in terms of the number of parameters and data fit (model deviance). These analyses were run in the program M-SURGE (Choquet et al. 2004). To enable identification of biological processes responsible for variation in survival rates, the total variance was decomposed into sampling variance and process variance (Gould and Nichols 1998), and the process variance was estimated with program MARK (White 1999). To compare process variance among the populations, the process variance was calculated relative to the maximum possible variance (Morris and Doak 2004).

The similarity of temporal variability in survival was calculated between all possible pairs among the 6 populations (Harris et al. 2005, and Table 2 in Appendix). The tests of covariate effects are based on an analysis analogous to analysis of variance, called ANODEV 
(Table 2 in Appendix). Under $\mathrm{H}_{0}$, the covariate did not explain any of the survival variance. To assess the effects of covariates, the amount of variation in survival accounted for by covariates $\left(\mathrm{R}^{2}\right)$ was estimated according to the model's deviance (Table 2 in Appendix, Gaillard et al. 1997), or the process variance (calculated as $\left(\sigma^{2}-\sigma_{\text {res }}^{2}\right) / \sigma^{2}$, where $\sigma^{2}$ refers to the total process variance and $\sigma_{\text {res }}^{2}$ to estimated residual variance when the effects of covariate are accounted for; see Loison et al. 2002) .

\section{Results}

\section{Recapture rates}

The most parsimonious model constrained detection probabilities to vary between years with additive trap happiness for males in Corsica and females in Crete, and with differences between sexes in the localities of Frioul, Corsica and Crete (Table 1a). Recapture rates were

highly divergent across study sites (Fig. 2a), and this is due to the differences in sampling schemes of the monitoring programs. For example, on Lavezzi capture-recapture efforts occurred during the pre-laying stage when females visit their nests irregularly, whereas males visit them nearly every night. This favored the capture of males versus females.

\section{Adult survival}

The mean annual adult survival rate of Cory's shearwater was 0.90 and the relative process variance (i.e process variance taken relative to the maximum possible variance) is 0.0049 . Mean annual adult survival ranges from $0.83 \pm 0.0016$ (mean \pm relative process variance) for both sexes in Malta to $0.95 \pm 0.009$ for females from Selvagem (Fig 3a). There is evidence of a longitudinal gradient among the population (ANODEV $\mathrm{p}=0.04$ Table 2, Fig 3a), with 34\% of the variation among populations explained by a longitudinal gradient. There is no evidence of a body mass effect on adult survival (ANODEV $\mathrm{p}=0.43$, Table 2), although there is a tendency for larger birds to have higher survival rates (Fig 3b). 
The most parsimonious model constrained adult survival to vary synchronously between localities, with differences between sexes in Crete and a transient effect in Selvagem (Table 1b). Adult survival probabilities were not dissimilar between the following groups: 1) both females and males from Selvagem, Corsica, Tremiti, 2) both females and males from Frioul and females from Crete, and 3) both females and males from Malta and males from Crete (Fig 2b). Adult survival probabilities varied from year to year between 1) 0.88 and $0.96,2$ ) 0.82 and 0.92 , and 3) between 0.74 and 0.88 . Lower survival rates occurred in 1990 and 1995; if these values are excluded, the relative process variance relative is reduced by $82 \%$ (0.09). The fraction of variability accounted for by the common patterns among possible pairs of localities ranges from $37 \%$ for Frioul/Crete to $92 \%$ for Tremiti /Malta, and is overall very high (average 71\%) (Table 3). The temporal adult survival variations are affected by SOI (ANODEV $\mathrm{p}<0.0001$, Table 4, Fig. 3c), but not by NAO (Table 4). The proportion of explained variation in survival by SOI was high $(92 \%$ based on deviance and $62 \%$ based on the process variance).

\section{Discussion}

Our results showed that temporal variations in Cory's shearwater adult survival from 6 breeding populations were synchronized over a wide range of the species' distribution between 1989 and 1997. Adult survival varied between 0.88 and 0.96 for birds breeding in Selvagem, Corsica and Tremiti Islands, 0.82 and 0.92 for females breeding in Crete and birds from Frioul Island and between 0.74 and 0.88 for males breeding in Crete and birds from Malta.

Adult survival varied little from year to year, except during 1990 and 1995, where it decreased strongly. As expected for a long-lived species such as the Cory's shearwater, the interannual adult survival variations are small because of the effect of environmental 
canalization (Saether and Bakke 2000, Gaillard and Yoccoz 2003). If the 1990 and 1995 lower adult survival years are removed, the process variance of adult survival drops by $82 \%$. These results suggest that extreme events might be a likely factor affecting adult survival of Cory's shearwater.

Synchronicity explains on average $71 \%$ of adult temporal variations. Spatial synchronization of annual survival rates might be caused by the effect of environmental conditions during the non-breeding season, when migratory seabirds originating from different breeding populations congregate in similar areas (Schaub et al 2005). Cory's Shearwaters appeared to migrate to a widespread range in the South Atlantic, with birds breeding in the Atlantic (Selvagem) wintering more westward than those breeding in the Mediterranean (Ristow et al. 2000). The widespread distribution during winter over a vast oceanic range allows seabirds to leave an area with adverse weather or trophic conditions (Harris et al. 2005), and extreme environmental events occurring at large spatial scale may be a likely factor affecting adult survival. Wrecks of large numbers of seabirds, including Cory's Shearwaters, have been recorded related to autumn and northern-winter storms in the course of migration and wintering area of Cory's shearwater (Brichetti et al. 2000).

Our results support the hypothesis that extreme events due to large scale climate oscillations occurred during the non-breeding season and influenced Cory's shearwater adult survival. The SOI appears to be an important source for the temporal variation of Cory's shearwater adult survival, whereas the NAO has no effect. The NAO affects the North Atlantic and Mediterranean climate where the breeding populations are located, whereas the effect of the SO is expected only during the non-breeding season when the birds migrate southward in the Atlantic. Adult survival is negatively affected by the SOI (positive SOI values indicated La Niña years), with at least $62 \%$ of variation in survival explained by SOI fluctuations. During La Niña years, the greater number of Atlantic hurricanes and storms may 
cause a decrease in adult survival for Cory's shearwater. Wrecks of pelagic seabirds following hurricanes and storms generally tend to be dominated by juvenile birds rather than adults. Therefore, the effect of storms during La Niña suggested here for adults, will likely affect juvenile survival even more.

Our results showed that large scale climate forces affect and synchronize the adult survival of wide ranging migratory bird over its entire range. The consequences of this result in terms of population dynamics depend on complex demographic processes (e.g fecundity, recruitment, immigration, density dependence and so on) and require modeling the metapopulation, which is not in the scope of this study. However, we speculate that the spatial synchronization of annual survival variations may unlikely translate into the spatial synchronization of inter-annual fluctuations in populations. Indeed, for long-lived species, Saether and Bakke (2000) suggested that variation in fecundity and recruitment contribute more to the population fluctuations than variations in adult survival. Spatial synchronization of fecundity and recruitment variability is unlikely for seabirds because the potential factors affecting them (e,g. ocean productivity around the breeding site, habitat quality, predation etc.) may differ significantly among geographically distinct populations. Nevertheless, the synchronized reduction in adult survival for all populations during extreme climate events may likely have a direct consequence on the meta-population because long-lived species population growth rate is very sensitive to adult survival. Ultimately, it will result in higher species extinction risk, especially if extreme climate events become more frequent.

Our results also highlight that mean adult survival rates differed between populations and between sexes for birds breeding in Crete. A longitudinal gradient explains 34\% of the variance observed among mean adult survival. Adult survival is higher for birds breeding in the Atlantic (mean \pm relative process variance: $0.95 \pm 0.03$ for females, $0.93 \pm 0.04$ for males 
in Selvagem $)$, than in the eastern part $(0.89 \pm 0.03$ for females, $0.83 \pm 0.03$ for males in Crete). Several non exclusive factors potentially explain this observed longitudinal gradient, including oceanographic constraints around the breeding populations, body size, and human impacts.

Oceanographic productivity around the breeding populations decreases eastward. The eastern Mediterranean is a nutrient-poor region with low productivity (Caddy et al. 1995). In the western Mediterranean, productivity is enhanced by cooler water from large rivers and currents from Atlantic along North Africa coasts (Margalef 1985, Caddy et al. 1995). Between Morocco and Selvagem Islands in the Atlantic, productivity is enhanced by strong upwelling with colder and richer waters (Freudenthal et al. 2002).

Previous studies showed a longitudinal gradient in body size, with larger birds in the Atlantic than in the eastern Mediterranean (Rabouam et al. 1998). This is probably a result of the selective pressure in relation to the observed water productivity gradient. Our analysis does not support an effect of body mass on Cory's shearwater. However, body weight had been collected at random, and the random weight of an individual varies by $15 \%$ within days whereas the weight distribution of a population shows a much smaller standard deviation (Ristow and Wink 1980). To study the influence of body size on adult survival, the quality of the data should be improved in future studies by taking weights only at the end of the prelaying period to minimize the variation in weight among individuals, or by using measurements of skeletal features of birds.

Harvesting of Cory's shearwater and incidental by-catch by longline fisheries may also influence adult survival, with contrasting effects between the Atlantic and Mediterranean. Sixty-six percent of the birds killed as incidental by-catch are mainly adult Cory's shearwaters around Columbretes Islands in the Western Mediterranean (Belda and Sánchez 2001). Interaction with fisheries varies depending on location (Cooper et al. 2003), 
but more information is needed to quantify the impact of longline fisheries on Cory's shearwater mortality. The practice of harvesting of birds has sharply declined among most Mediterranean populations since the 1970 s, with the exception of in the Sicily channel where birds are killed illegally by fishermen in Malta (Borg and Cachia-Zammit 1998). Birds breeding in Malta showed the lowest adult survival $(0.827 \pm 0.03$ for females, $0.833 \pm 0.03$ for males), highlighting the effects of human harvesting.

\section{Conclusion}

Despite uncertainties over causal mechanisms, these findings add to the body of evidence that large scale climate variations could affect seabird adult survival over large spatial scales. We argue here that for long-lived seabird species, adult survival is buffered against regular environmental variability. Extreme climate conditions, such as storms, significantly affect adult survival at large spatial scales during the non-breeding period. Whatever the exact causes may be, the effects of large scale climatic processes are dramatic for species with high adult survival and low fecundity since even minimal reductions in survival have large effects on population trends. Moreover, we showed here that variation in adult survival was synchronized over the entire distribution of the Cory' shearwater, resulting in reduced persistence of meta-populations. The future of such long-lived seabirds species has the potential to be dire under future global changes, especially since there are predictions of higher frequency extreme large scale climatic events, such as El Niño / La Niña events.

Acknowledgements - We acknowledge the reviewers for their helpful comments that greatly improved the manuscript. We thank C. Strasser for her English corrections. We are grateful to Oscar Fernandez who collected all field data on Frioul and allowed access to his original field data; to Ugo F. Foschi who has help to collect data on Tremiti Islands; to the staff of the 
Bouches-de-Bonifacio Nature Reserve for providing accommodation and facilities, and to the Greek Ministry of Agriculture who provided facilities for the field study in Crete. The study of Cory's shearwater breeding on Lavezzi Island in Corsica was a personal program of the Centre de Recherches sur les Populations d'Oiseaux (Paris). Financial support of this analysis come from a Life program conducted on Cory's shearwater at Frioul Island. 


\section{References}

Altwegg R, Roulin A, Kestenholz M, Jenni L (2006) Demographic effects of extreme winter weather in the barn owl. Oecologia, 149, 44-51.

Anderson DR, Burnham KP (1999) General strategies for the analysis of ringing data. Bird Study, 46, S261-270.

Barbraud C, Weimerskirch H (2003) Climate and density shape population dynamics of a marine top predator. Proceedings of the Royal Society.

Belda EJ, Sánchez A (2001) Seabird mortality in the western Mediterranean: factors affecting bycatch and proposed mitigating measures. Biological Conservation, 98, 357-363

Borg JJ, Cachia-Zammit R (1998) Monitoring Cory's Shearwater Calonectris diomedea populations in a hostile environment. In : Ecologie des oiseaux marins et gestion intégrée du littoral en Méditerranée (Walmsley J, Goutner V, El Hili A, Sultana J Eds) IV Symposium méditerranée des oiseaux marins, Hammamet.

Bretagnolle V, Lequette B (1990) Structural Variation in the Call of the Cory's Shearwater. Ethology, 85, 313-323

Brichetti P, Foschi UF, Boano G (2000) Does El Niño affect survival rate of Mediterranean populations of Cory's Shearwater? Waterbirds, 23, 147-154

Caddy JF, Refk R, Do-Chi T (1995) Productivity estimates for the Mediterranean: evidence of accelerating ecological change. Ocean \& Coastal Managemen, 26,1-18

Camphuysen CJ, Van Der Meer J. (2001) Pelagic distribution, moult and (sub-) specific status of Cory's Shearwaters Calonectris (d.) diomedea/borealis wintering off southern Africa. Marine Ornithology, 29, 89-96. 
Choquet R, Reboulet AM, Pradel R, Gimenez O, Lebreton JD (2004) M-SURGE: new software specifically designed for multistate capture-recapture models. Animal Biodiversity and Conservation, 27, 207-215

Choquet R, Reboulet AM, Pradel R, Gimenez O, Lebreton JD (2005) U-Care user's guide, Version 22. Montpellier (ftp: //ftpcefecnrsfr/biom/Soft-CR/U-CARE)

Cooper J, Baccetti N Belda EJ, Borg JJ, Oro D, Papaconstantinou C, Sanchez A (2003) Seabird mortality from longline fishing in the Mediterranean Sea and Macaronesian waters: a review and a way forward. Scientia Marina, 67, 57-64

Crespin L, Harris M.P, Lebreton J.L, Wanless S (2006) Increased adult mortality and reduced breeding success with age in a population of common guillemot Uria aalge using marked birds of unknown age. Journal of Avian Biology, 37, 273-282

Duffy DC, (1990) Seabirds and the 1982-83 El Niño Southern Oscillation. In: Global Ecological Consequences of the 1982-1983 El Niño Southern Oscillation (eds Glynn), pp395-415, Elsevier Oceanographic Series 52.

Frederiksen M, Wanless S, Harris M.P, Rothery P, Wilson L (2004) The role of industrial fisheries and oceanographic change in the decline of North Sea black-legged kittiwakes. Journal of Applied Ecology, 41, 1129-1139

Frederiksen M, Harris M.P, Wanless S (2005) Inter-population variation in demographic parameters: a neglected subject? Oikos, 111, 209-214.

Freudenthal T, Meggersa H, Henderiksb J, Kuhlmanna H, Morenoc A and Wefera G (2002) Phosphorus Limitation of Primary Productivity in the Eastern Mediterranean Sea. Deep-Sea Research Part II

Gaillard JM, Boutin JM, Delorme D, Van Laere G, Duncan P and Lebreton JD (1997) Early survival in roe deer: causes and consequences of cohort variation in two contrasted populations. Oecologia, 112, 502-513 
Gaillard JM, Yoccoz NG (2003) Temporal variation in survival of mammals: a case of environmental canalization? Ecology, 84, 3294-3306

Gimenez O, Choquet R and Lebreton JD (2003) Parameter redundancy in multistate capturerecapture models. Biometrical Journal, 45, 704

Gould WR, Nichols, JD (1998) Estimation of temporal variability of survival in animal populations. Ecology, 79, 2531-2538

Hallett T.B., Coulson T., Pilkington J.G., Clutton-Brock T.H., Pemberton M., Grenfell B.T. (2004) Why large-scale climate indices seem to predict ecological processes better than local weather. Nature, 430, 71-75.

Harris MP, Anker-Nilssen T, McCleery RH, Erikstad KE, Shaw DN, Grosbois V (2005) Effect of wintering area and climate on the survival of adult Atlantic puffins Fratercula arctica in the eastern Atlantic. Marine Ecology Progress Series, 297, 283296

Hudson PJ (1985) Population Parameters for the Atlantic Alcidae. In: The Atlantic Alcidae (eds Nettleship DN, Birdhead TR), pp. 233-261. Academic Press, London.

Jenouvrier S., Barbraud C. and Weimerskirch. H. (2003) Effects of climate variability on the temporal population dynamics of southern fulmars. Journal of Animal Ecology, 72, $576-587$.

Jenouvrier S, Barbraud C, Weimerskirch H (2005) Long-term contrasted responses to climate of two Antarctic seabirds species. Ecology, 86, 2889-2903

Jenouvrier S., Tavecchia G, Thibault J.-C., Choquet R., Bretagnolle V. (2008). Recruitment processes in long-lived species with delayed maturity: estimating key demographic parameters. Oikos. 
Lebreton JD, Clobert J (1990) Bird population dynamics, management and conservation: the role of mathematical modelling In: Bird population studies: their relevance to conservation and management (eds Perrins CM, Lebreton JD, Hirons GJM) Oxford University Press, Oxford, UK

Lebreton JD, Burnham KP, Clobert J, Anderson DR (1992) Modeling survival and testing biological hypotheses using marked animals: a unified approach with case studies. Ecological Monograph, 62, 67-118

Loison A, Sæther B.E, Jerstad K, Røstad O.W. (2002) Disentangling the sources of variation in the survival of the European dipper. Journal of Applied Statistics, 29, 289- 304

Margalef (1985) Environmental control of the mesoscale distribution of primary producers and its bearing to primary production in the western Mediterranean. IN Mediterranean Marine Ecosystems (eds Moraitou-Apostopoulou M, Kiortsi V.) pp. 213-229. Plenum Press, New York.

Morris WF, Doak DF (2004) Buffering of Life Histories against Environmental Stochasticity: Accounting for a Spurious Correlation between the Variabilities of Vital Rates and Their Contributions to Fitness. American naturalist, 163, 579-590.

Mougin JL, Jouanin C, Roux R (2000) Démographie du Puffin cendré Calonectris diomedea de Selvagem Grande (3009`N, 1552’W). Revue d'Écologie, 55, 275-290

Ottersen G, Planque B, Belgrano A, Post E, Stenseth NC (2001) Ecological effects of the North Atlantic Oscillation. Oecologia, 128, 1-14

Pradel R. 1993. Flexibility in survival analysis from recapture data: handling trapdependence. IN Marked individuals in the study of bird populations (eds Lebreton J.D, North P.M.) pp 29-37. Birkhäuser Verlag, Basel, Switzerland.

Rabouam C, Bretagnolle V, Thibault J-C (1998) Geographic variation in the breeding biology of the Cory's Shearwater: an effect of body size or environment? In: Ecologie des 
oiseaux marins et gestion intégrée du littoral en Méditerranée. $4^{\text {ème }}$ Symposium méditerranéen des oiseaux marins, Hammamet.

Ristow D, Wink M (1980) Sexual Dimorphism of Cory's Shearwater. Il-Merill, 21, 9-12

Ristow D, Berthold P, Hashmi D, Querner U (2000) Satellite tracking of Cory's Shearwater migration. Condor, 102, 696-699

Rolland V, Barbraud C, Weimerskirch W (2007) Combined effects of fisheries and climate on a migratory long-lived marine predator. Journal of Applied Ecology

Royama T (1992) Analytical population dynamics. Chapman and Hall.

Saether BE, Bakke O (2000) Avian life history variation and contribution of demographic trait to the population growth rate. Ecology, 81, 642-653

Sandvik H, Erikstad K, Barrett R, Yoccoz G (2005) The effect of climate on adult survival in five species of North Atlantic seabirds. Journal of Annimal Ecology, 74, 817-831

Sarà M. (1993) Feeding habits of Cory's shearwater (Calonectris diomedea) in the Central Mediterranean Sea. In: Status and Conservation of Seabirds, (eds Aguilar,JS, Monbailliu X, Paterson AM), pp 213-220. Proceeding of the $2^{\text {nd }}$ Mediterranean Seabird Symposium MEDMARAVIS/SEO, Madrid.

Schaub M, Wojciech K, Koppens U (2005) Variation of primary production during winter induces synchrony in survival rates in migratory white storks Ciconia ciconia. Journal of Animal Ecology, 74, 656-667

Stearns SC (1992) The evolution of life histories. Oxford University Press, Oxford

Stenseth NC, Ottersen G, Hurrel JW, et al. (2003) Studying climate effects on ecology through the use of climate indices: the North Atlantic Oscillation, El Niño Southern Oscillation and beyond. Proceedings of the Royal Society of London B, 270, 20872096 
Stenseth NC, Ottersen G, Hurrel JW, Belgrano A (2004) Marine Ecosystems and climate Variation : The North Atlantic: A Comparative Perspective. Oxford University Press

Tavecchia G, Pradel R, Boy V, Johnson A, Cézilly F (2001) Sex- and age-related variation in survival probability and the cost of the first reproduction in breeding Greater Flamingos. Ecology, 82, 165-174

Thibault JC, Rabouam C, Bretagnolle V (1997) Calonectris diomedea Cory's Shearwater. Birds of the Western Palearctic, Update 1, 75-98

Walther GR, Post E, Convey P, et al (2002) Ecological responses to recent climate change. Nature, 416, 389-395.

White GC, Burnham KP (1999) Program MARK : Survival estimation from populations of marked animals. Bird Study, 46 supplement, 120-138. 
Jenouvrier et al.

Table 1: Modeling (a) capture and (b) survival probabilities for Cory's Shearwater. Akaike's information criterion corrected for small sample size (AICc) is used for model comparison, and for the identification of the best model (lowest AICc). $\triangle \mathrm{AICc}$ is the difference of AIC between the specified model and the best one (i.e. $\triangle \mathrm{AICc}=0$ for the best model) in each table. $k$ refers to the number of parameters estimated and Dev to the deviance of the model. The CJS model is $\Phi_{t} \mathrm{P}_{t}$, with the survival probability $(\Phi)$ and capture probability $(\mathrm{P})$ varying with time $(t)$. An effect of sex on survival or capture rate is denoted by $s$, the letter $m$ denotes apparent "trap happiness" on recapture rates, and a transient effect on adult survival is denoted by $a 2$ (see methods for more details). 
a)

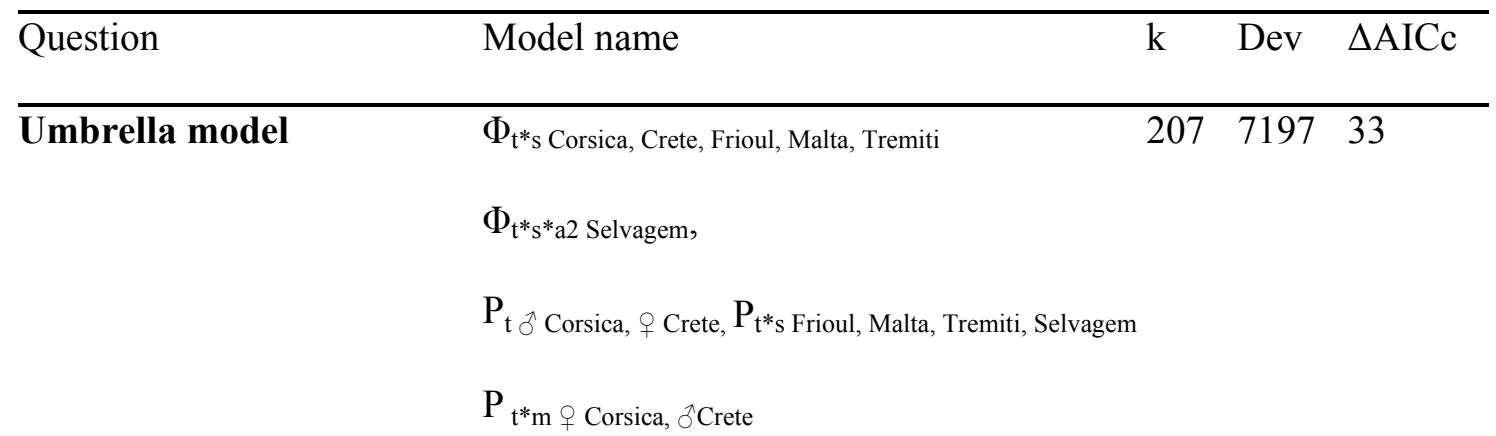

1. Trap dependence effect? $\mathrm{P}_{\mathrm{t}^{*} \mathrm{~s}}$ Corsica, Crete, Frioul, Malta, Tremiti, Selvagem $\quad 193 \quad 7247 \quad 55$

2. Additive trap $\quad \mathrm{P}_{\mathrm{t}^{*} \mathrm{~s}}{ }^{\top}$ Corsica, , Crete, Frioul, Malta, Tremiti, Selvagem $197 \quad 7219 \quad 35$

dependence effect? $\quad \mathrm{P}_{\mathrm{t}+\mathrm{m}}+$ Corsica, $\delta^{\lambda}$ Crete

3. Additive sex effect? $\quad P_{t+s \text { Frioul, Malta, Tremiti, Selvagem }} \quad 1617261 \quad 5$

$\mathrm{P}_{\mathrm{t}+\mathrm{s}+\mathrm{m} \text { Corsica, Crete }}$

4. Sex effect according to $P_{t \text { Frioul, Malta, Tremiti, Selvagem }} \quad \begin{array}{lll}7279 & 15\end{array}$

different study sites? $\quad \mathrm{P}_{\mathrm{t}+\mathrm{s}+\mathrm{m} \text { Corsica, Crete }}$

for sake of simplicity we $\quad \mathrm{P}_{\mathrm{t} \text { Malta, Tremiti, Selvagem }} \quad 158 \quad 7262 \quad 0$

don't showed the test for $\quad \mathrm{P}_{\mathrm{t}+\mathrm{s} \text { Frioul }}$

each study site $\quad \mathrm{P}_{\mathrm{t}+\mathrm{s}+\mathrm{m} \text { Corsica, Crete }}$

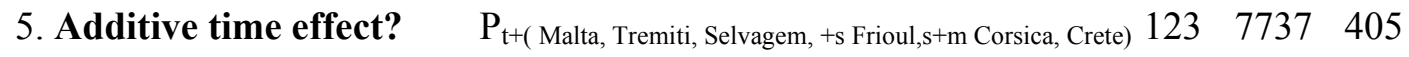

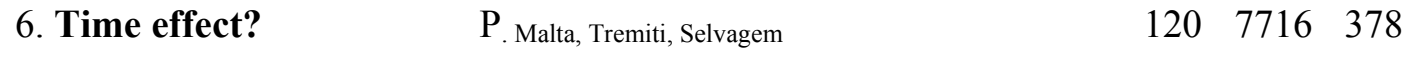

$\mathrm{P}_{\mathrm{s} \text { Frioul }}$

$\mathrm{P}_{\mathrm{s}+\mathrm{m} \text { Corsica, Crete }}$ 
b)

\begin{tabular}{|c|c|c|c|}
\hline Question & Model name & $\mathrm{k}$ & Dev $\triangle \mathrm{AICc}$ \\
\hline Umbrella model & $\begin{array}{l}\Phi_{\mathrm{t} * \mathrm{~s} \text { Corsica, Crete, Frioul, Malta, Tremiti }} \\
\Phi_{\mathrm{a} 2 *^{*} *_{\mathrm{s}} \text { Selvagem }} \\
\mathrm{P}_{\mathrm{t} \text { Malta, Tremiti, Selvagem }} \\
\mathrm{P}_{\mathrm{t}+\mathrm{s} \text { Frioul }} \\
\mathrm{P}_{\mathrm{t}+\mathrm{s}+\mathrm{m} \text { Corsica, Crete }}\end{array}$ & 158 & 726272 \\
\hline 1. Transient effect? & $\Phi_{t} *_{\mathrm{s}}$ Corsica, Crete, Frioul, Malta, Tremiti, Selvagem & 145 & 730286 \\
\hline 2. Additive transient effect? & $\begin{array}{l}\Phi_{\mathrm{t} *_{\mathrm{s}} \text { Corsica, Crete, Frioul, Malta, Tremiti }} \\
\Phi_{(\mathrm{a} 2+\mathrm{t}){ }^{*} \mathrm{~s} \text { Selvagem }}\end{array}$ & 148 & 727363 \\
\hline 3. Additive sex effect? & $\begin{array}{l}\Phi_{\mathrm{t}+\mathrm{s} \text { Corsica, Crete, Frioul, Malta, Tremiti }} \\
\Phi_{\mathrm{a} 2+\mathrm{t}+\mathrm{s} \text { Selvagem }}\end{array}$ & 109 & 731224 \\
\hline 4. Sex effect according to & $\Phi_{\mathrm{t} \text { Corsica, Crete, Frioul, Malta, Tremiti }}$ & 98 & 732212 \\
\hline different study sites? & $\Phi_{\mathrm{a} 2+\mathrm{t} \text { Selvagem }}$ & & \\
\hline for sake of simplicity we & $\Phi_{\mathrm{t}}$ Corsica, Frioul, Malta, Tremiti & 101 & 731511 \\
\hline didn't showed the test for & $\Phi_{\mathrm{t}+\mathrm{s} \text { Crete }}$ & & \\
\hline each study site & $\Phi_{\mathrm{a} 2+\mathrm{t} \text { Selvagem }}$ & & \\
\hline 5. Additive time effect? & $\Phi_{\mathrm{t}+(\text { Corsica, Frioul, Malta, Tremiti, } \mathrm{s}+\text { Crete, a2+Selvagem) }}$ & 68 & 73777 \\
\hline 6. Time effect according to & $\Phi_{t+}\{1 .($ Corsica, Tremiti, a2 Selvagem); & 64 & 73780 \\
\hline different study sites? & 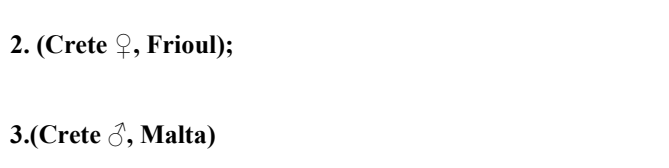 & & \\
\hline All the possible combinations & Ф. \{1.(Corsica, Tremiti, a2 Selvagem), & 57 & 741321 \\
\hline of study sites are not showed & 2. (Crete + , Frioul, $)$ & & \\
\hline here for sake of simplicity & 3. $($ Crete $\hat{\alpha}$, Malta) $\}$ & & \\
\hline
\end{tabular}


Jenouvrier et al.

Table 2: Effect of longitude and body size on adult survival variation of the six studied populations of Cory's Shearwater. Dev is the deviance, $k$ the number of parameters estimated, while IC refers to the $95 \%$ confidence intervals of the slope. To assess the effect of covariates, we determined whether the slope of the relationship between adult survival and the environmental variable were significant (i.e. does 0 belong to the confidence interval of the slope estimate?). If the slope is significant, we thus used the ANODEV to test for the covariate effect. The threshold p-value used for ANODEV was 0.05. We estimated the proportion of explained temporal variation in adult survival accounted by covariates $\left(\mathrm{R}^{2}\right)$ based on the process variance $(\sigma)$, and based on the deviance respectively.

\begin{tabular}{|c|c|c|c|c|c|c|c|c|}
\hline \multirow[b]{2}{*}{ models } & \multirow[b]{2}{*}{ Dev } & \multirow[b]{2}{*}{$\mathrm{k}$} & \multirow[b]{2}{*}{ slope } & \multirow[b]{2}{*}{ ICL } & \multicolumn{3}{|c|}{ ANODEV } & \multirow{2}{*}{$\begin{array}{c}\mathrm{R}^{2}-\sigma \\
\text { Dev }\end{array}$} \\
\hline & & & & & $\mathrm{ICH}$ & $\mathrm{F}(1,11)$ & p-value & \\
\hline $\begin{array}{c}\text { Sex*study } \\
\text { sites }\end{array}$ & 7431.1 & 65 & & & & & & \\
\hline Longitude & 7455.3 & 55 & -0.0015 & -0.023 & -0.006 & 5.7 & 0.04 & $30-34$ \\
\hline Body size & 7465.8 & 55 & 0.0730 & -0.027 & 0.173 & & & \\
\hline Constant & 7467.9 & 54 & & & & & & \\
\hline
\end{tabular}


Jenouvrier et al.

Table 3: Covariation among study sites time series from 1989 to 1997.

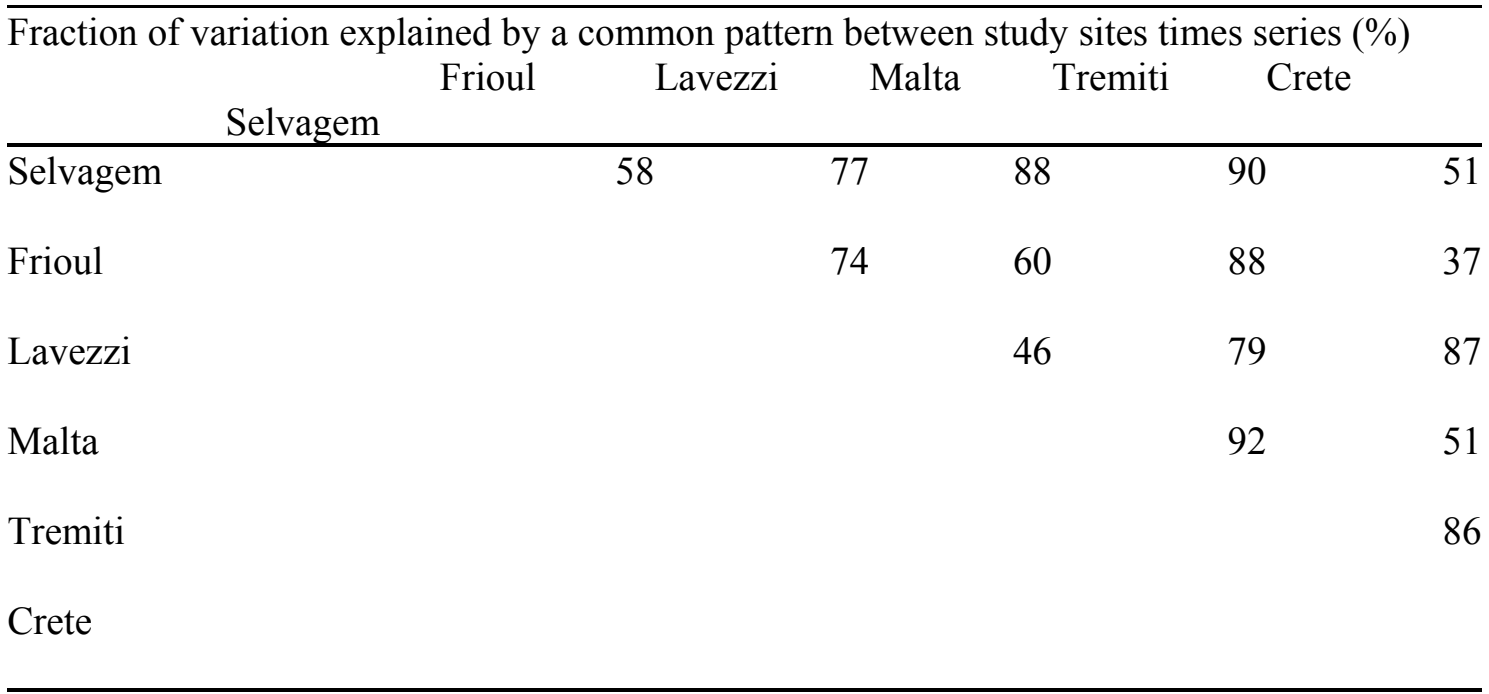


Jenouvrier et al.

Table 4: Effect of SOI and NAO on adult survival variation of the six studied populations of Cory's Shearwater. See table 3 for legends. The threshold p-value used for ANODEV is 0.05 and a Bonferroni correction for two tests is applied.

\begin{tabular}{lllllllll}
\hline models & Dev & $\mathrm{k}$ & slope & ICL & ICH & ANODEV & $\mathrm{R}^{2}$ \\
& & & & & p $(1,7)$ & & \\
\hline Time & 7378.1 & 64 & & & & & & \\
SOI & 7408.2 & 58 & $-0,22$ & $-0,41$ & $-0,04$ & 78.7 & $<0.0001$ & $62-92$ \\
NAO & 7713.1 & 58 & $-0,09$ & $-0,47$ & 0,29 & & & \\
Constant & 7746.7 & 57 & & & & & & \\
\hline
\end{tabular}


Figure legends

Fig. 1. Map of the study sites of the six studied populations of Cory's Shearwater.

Fig. 2. a) Capture probabilities and b) survival rates according to study sites. Estimates \pm

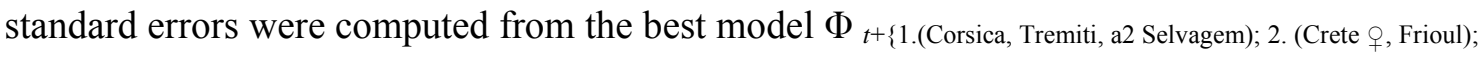

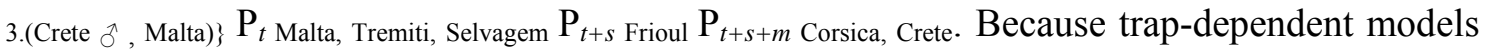
have severe identifiability problems (Pradel 1993), we showed the estimates of adult survival from Corsica and Frioul in 1996, computed by another analysis over the entire period of the study (unpublished results). The estimates \pm standard errors were computed from the best model $\Phi_{t} \mathrm{P}_{t^{+s+m}}$ and $\Phi_{t} \mathrm{P}_{t+s}$ for Corsica between 1978-2004 and Frioul between 1981-2004, respectively. For the sake of visibility we represented the variability in detection probabilities in two panels.

Fig. 3. Cory's Shearwater mean adult survival rate for both sexes and across studies sites as a function of a) longitude and b) body mass. Grey diamonds represent females and black squares represent males. Estimates \pm standard errors are computed from the model $\Phi$ (Crete, Corsica, Frioul, Malta, Tremiti, a2 Selvagem,)*s.

c) Temporal variations in Cory's Shearwater adult survival rate between 1989 and 1997 as a function of the southern oscillation index for the three groups 1) both females and males from Selvagem, Corsica, Tremiti (black circle), 2) both females and males from Frioul and females from Crete (triangle), and 3) both females and males from Malta and males from Crete (black square). Estimates \pm standard errors are computed from the best model $\Phi_{t+1}$.(Corsica, Tremiti, a2 
Jenouvrier et al.

Fig.1.

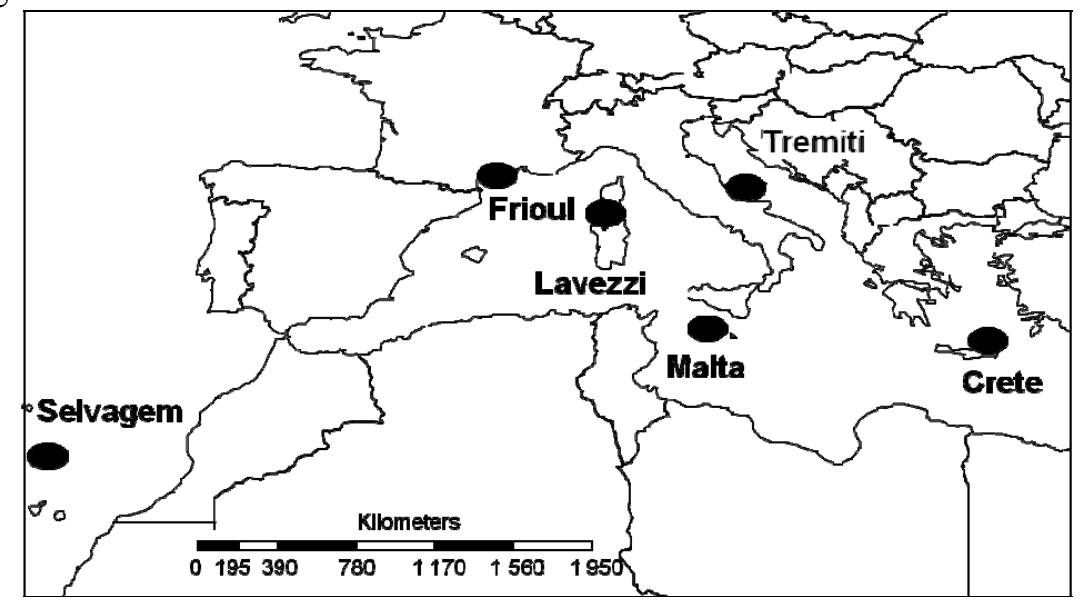


Jenouvrier et al.

Fig. 2.

a)

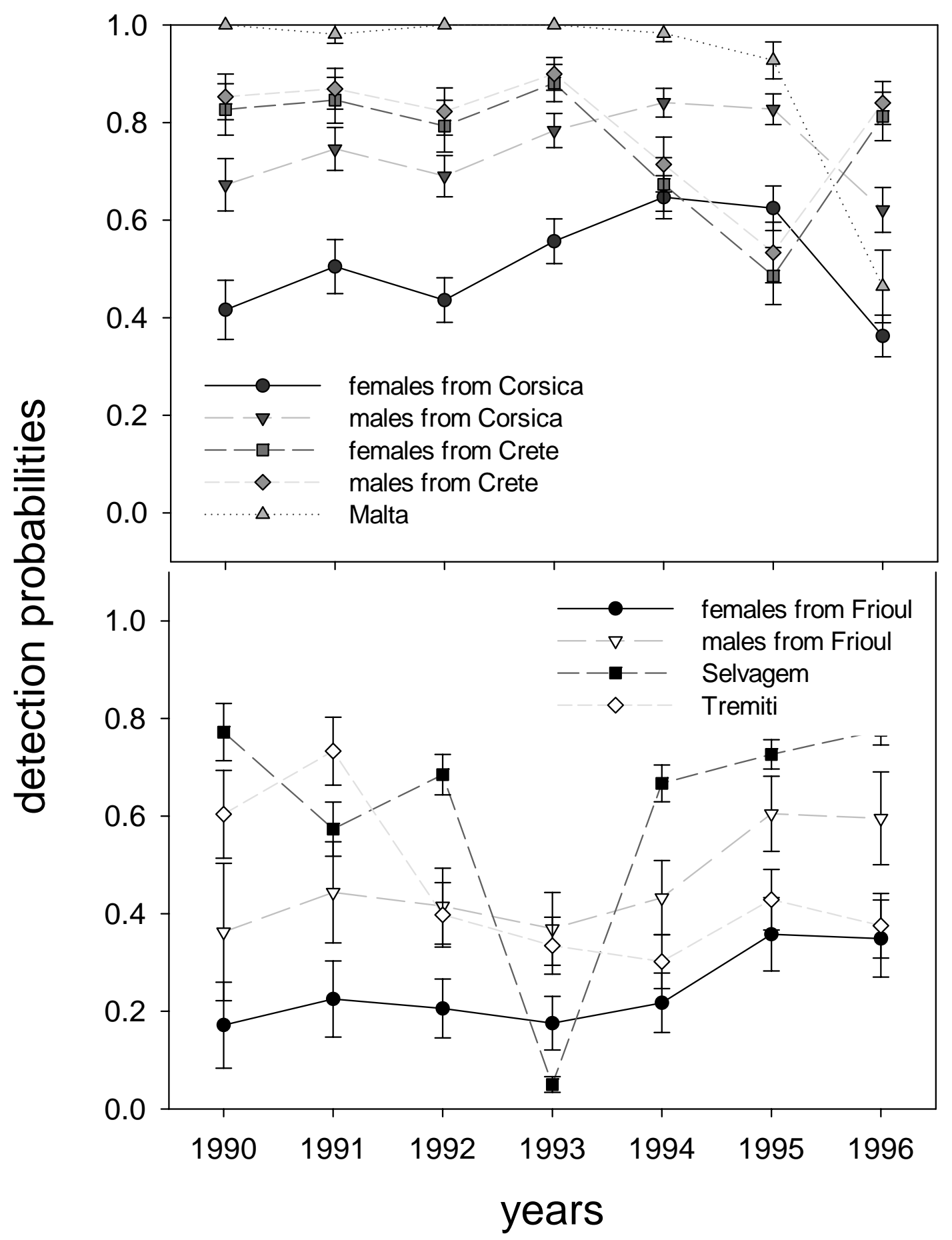


b)

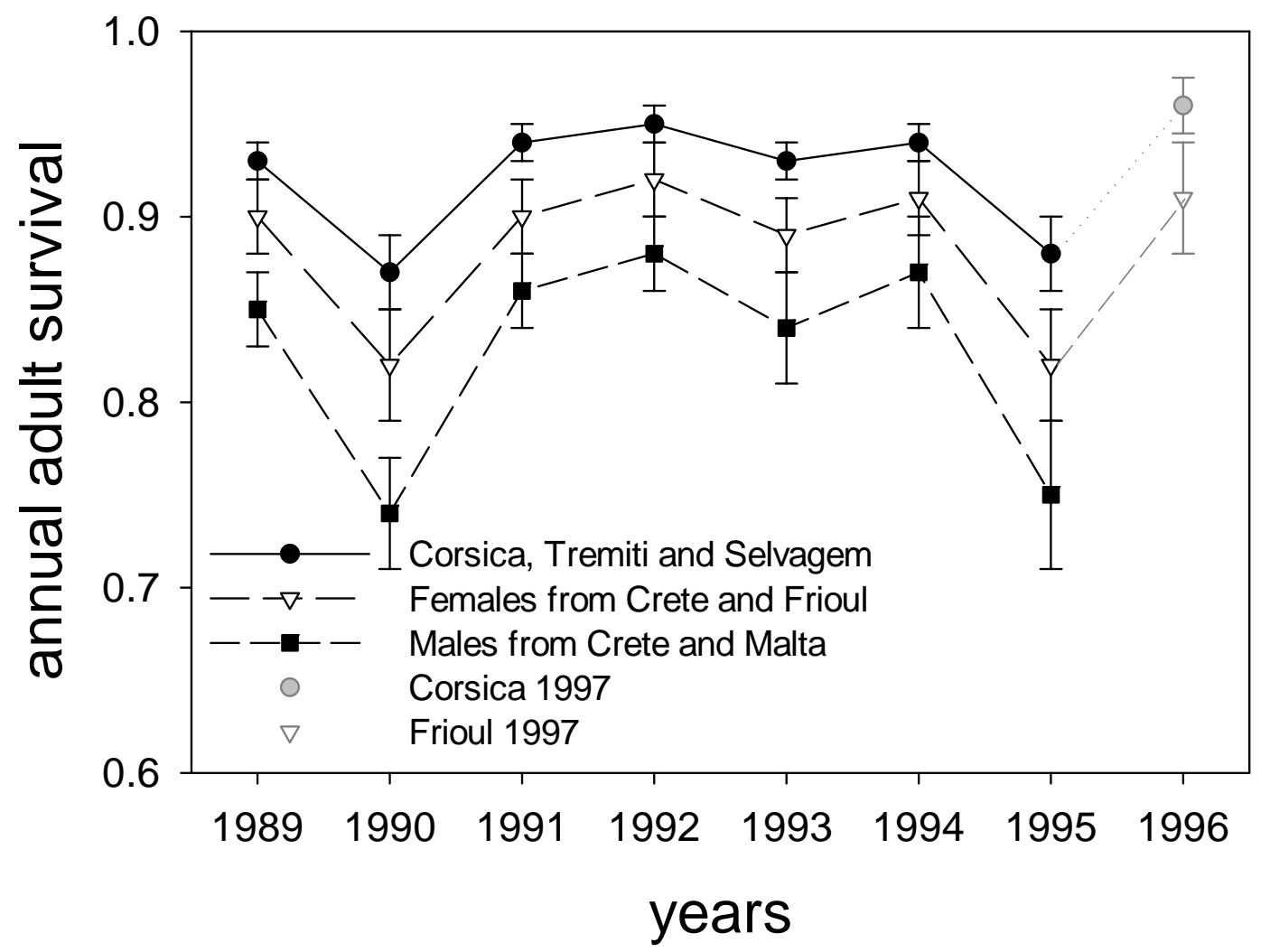


Jenouvrier et al.

Fig. 3.

a)

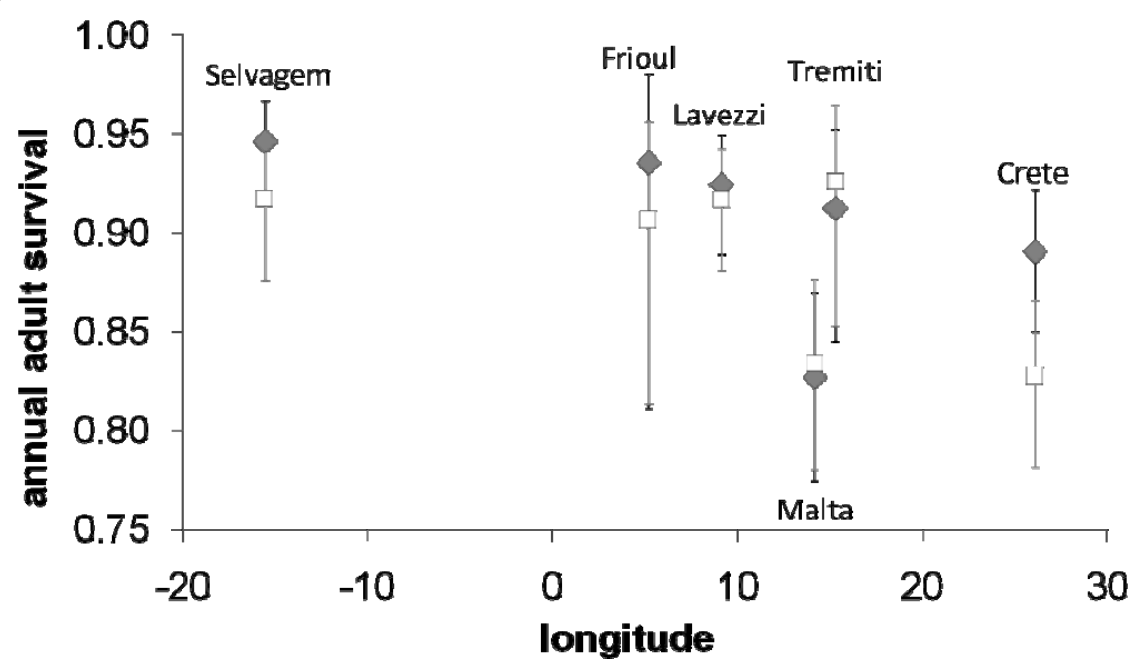

b)

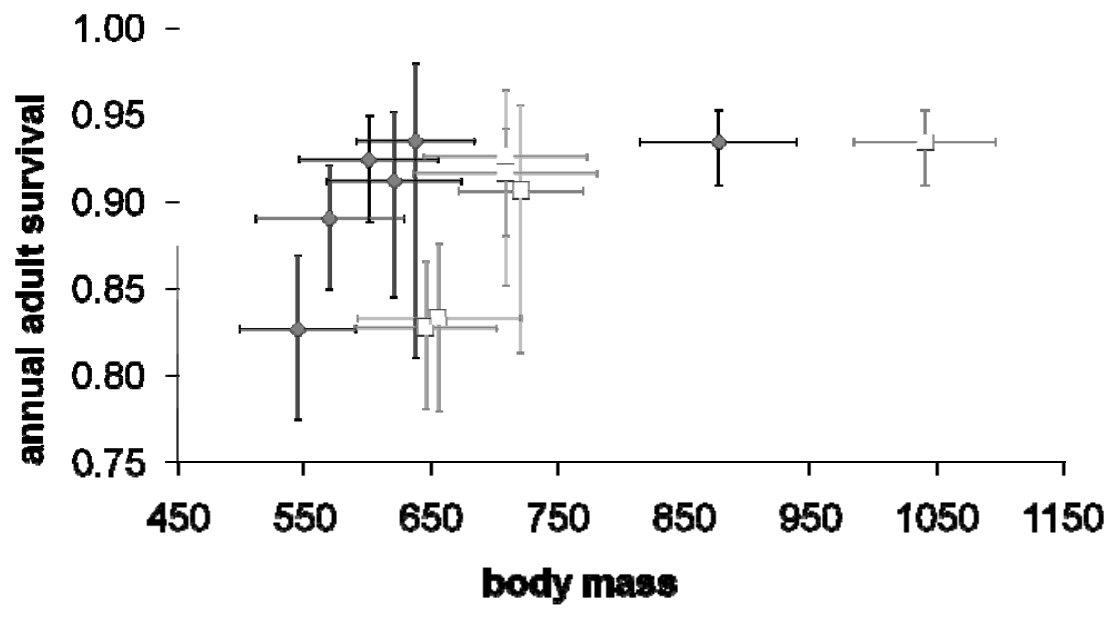

c)

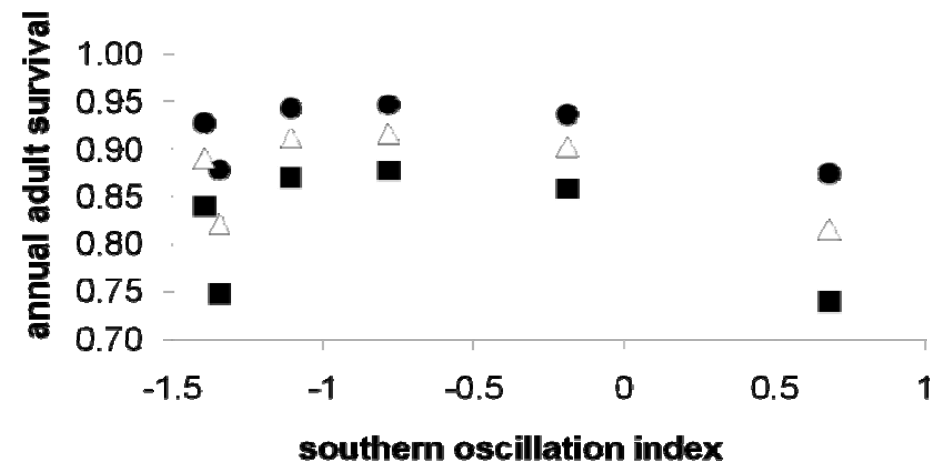

